Quim. Nova, Vol. 35, No. 1, 108-113, 2012

\title{
AVALIAÇÃO DA NATUREZA DA ATIVIDADE CATALÍTICA DE COMPOSTOS DE BISMUTO EM REAÇÕES DE METANÓLISE DO ÓLEO DE SOJA
}

\author{
Fabiano Rosa da Silva, Ricardo José Brugnago, Rafael Marangoni, Claudiney Soares Cordeiro, Shirley Nakagaki, \\ Fernando Wypych e Luiz Pereira Ramos* \\ Departamento de Química, Universidade Federal do Paraná, CP 19081, 81531-990 Curitiba - PR, Brasil
}

Recebido em 20/2/11; aceito em 28/5/11; publicado na web em 22/7/11

\begin{abstract}
ASSESSMENT OF THE CATALYTIC PROPERTIES OF BISMUTH COMPOUNDS IN SOYBEAN OIL METHANOLYSIS. Sodium bismuthate dihydrate and two species derived from its thermal treatment were investigated as catalysts for soybean oil methanolysis and, regardless of the type of solid used, ester yields always above $76 \mathrm{wt} \%$ were obtained. After a single reaction course, both liquid and solid phases were characterized using several analytical methods such as X-ray diffraction and thermogravimetric analysis. As a result, the catalytic phenomenon was shown to be solely due to the leaching of alkalinecatalytic species from the solid materials.
\end{abstract}

Keywords: biodiesel; bismuth; transesterification.

\section{INTRODUÇÃO}

A viscosidade dos óleos vegetais é cerca de 11 a 17 vezes maior que a do diesel de petróleo e esta propriedade dificulta o seu uso direto em motores de combustão por compressão interna (ciclo Diesel). Altas viscosidades causam a má atomização do combustível na câmara de combustão, gerando queimas parciais que resultam na formação de depósitos e gomas nos bicos injetores, nos cilindros e em outras partes internas do motor. ${ }^{1-4}$ Por esta razão, óleos vegetais in natura têm que ser pré-aquecidos para que o sistema de injeção opere normalmente e o motor apresente um desempenho adequado. ${ }^{1}$ Além disso, a combustão de triacilgliceróis também está associada à emissão de acroleína, substância tóxica e cancerígena que é formada pela decomposição térmica do glicerol. ${ }^{5}$

Em meados do século passado, a transesterificação de óleos vegetais foi proposta como uma possível solução para este problema. Nesta reação, metanol ou etanol podem ser utilizados como reagentes, na presença de um catalisador ácido, básico ou enzimático, para produzir monoésteres graxos cujas propriedades físicas e químicas são adequadas ao uso combustível em motores do ciclo Diesel. ${ }^{2}$ Este combustível, de origem renovável, foi então denominado biodiesel pelos órgãos reguladores e pela comunidade científica internacional. No entanto, outras classes de biocombustíveis também vêm sendo classificadas genericamente como biodiesel, tais como hidrocarbonetos derivados da biomassa (incluindo materiais graxos de diferentes origens) por processos térmicos. Atualmente, o craqueamento, o hidrocraqueamento (processo H-Bio) e o eletrocraqueamento são os processos que vêm sendo mais discutidos no âmbito do Programa Nacional de Produção e Uso do Biodiesel (PNPB). ${ }^{6}$

Recentemente, a busca por processos industriais de maior viabilidade econômica tem levado ao desenvolvimento de rotas alternativas para a produção de ésteres graxos. Tais rotas estão baseadas na utilização de materiais de menor valor agregado, como óleos de frituras, gorduras residuais e óleos de descarte, que inevitavelmente possuem maior acidez. Por esta razão, a esterificação de ácidos graxos vem sendo identificada como uma importante alternativa para o setor, seja como procedimento para a correção da acidez de materiais graxos residuais ou como etapa de conversão dos ácidos graxos gerados por

\footnotetext{
*e-mail: luiz.ramos@ufpr.br
}

hidrólise a altas temperaturas e pressão, em um processo que vem sendo denominado hidroesterificação.

Historicamente, o processo industrial de maior viabilidade econômica para a produção do biodiesel é baseado na catálise alcalina em meio homogêneo, geralmente utilizando alcóxidos comerciais ou $\mathrm{NaOH}$ e $\mathrm{KOH}$ como precursores desta mesma espécie catalítica. Porém, neste processo, dependendo do teor de ácidos graxos livres da matéria-prima, o catalisador pode ser parcialmente consumido pela formação de sabões, favorecendo a emulsificação, diminuindo o rendimento da reação e dificultando a purificação dos produtos. ${ }^{2,5,7}$ Por outro lado, a transesterificação de óleos vegetais também pode ocorrer utilizando catalisadores ácidos inorgânicos ou orgânicos, como os ácidos sulfúrico, clorídrico e fosfórico e vários tipos de ácidos sulfônicos. Embora estes catalisadores forneçam elevadas conversões de óleos vegetais em monoésteres, a reação é lenta, exige elevadas temperaturas e razões molares e mais de $2 \mathrm{~h}$ para conversão completa. ${ }^{1}$ Neste sentido, vale ressaltar que o rendimento das reações de esterificação e transesterificação, independentemente do tipo de catalisador empregado, depende do deslocamento do equilíbrio químico em favor dos ésteres produzidos, a partir da otimização de parâmetros como a temperatura da reação e a concentração efetiva do catalisador, bem como a agitação do meio e o excesso estequiométrico do álcool reagente. ${ }^{1,2}$

Mais recentemente, catalisadores heterogêneos têm sido propostos como alternativa para a produção industrial de biodiesel por apresentarem vantagens técnicas, econômicas e ambientais sobre os catalisadores homogêneos. Sistemas heterogêneos ideais não levam à formação de emulsões, favorecem as etapas de separação e purificação dos produtos e diminuem a geração de efluentes líquidos, além de facilitarem a realização das operações de recuperação e reciclagem do catalisador, reduzindo os custos de processo e a geração de passivos ambientais. ${ }^{8}$ No entanto, muitas destas tecnologias ainda se encontram em seus estágios iniciais de desenvolvimento e vários catalisadores, citados na literatura como heterogêneos, sofrem modificações químicas durante a reação ou simplesmente lixiviam com muita facilidade, comprometendo a reciclabilidade das espécies catalíticas e a eventual caracterização do processo como efetivamente heterogêneo. ${ }^{9,10}$

Substâncias de diferentes famílias, como sais, óxidos, compostos lamelares, compostos de coordenação, argilominerais in natura ou ativados térmica ou quimicamente, materiais poliméricos e líquidos 
iônicos, vêm sendo testadas como possíveis catalisadores heterogêneos para a produção de biodiesel. ${ }^{11,12}$ Neste sentido, ácidos e bases de Lewis têm sido os mais amplamente investigados, pois, diferentemente dos ácidos e bases de Brönsted-Lowry, não lixiviam com facilidade e podem ser reciclados com maior eficiência.

Um complexo bimetálico de $\mathrm{Fe}^{2+}-\mathrm{Zn}^{2+}$, baseado na impregnação de copolímeros de polietilenoglicol e polipropilenoglicol com massa molar média de $5800 \mathrm{~g} \mathrm{~mol}^{-1}$, foi utilizado por Sreeprasanth et al. na metanólise do óleo de girassol refinado. ${ }^{13}$ Nas condições de 3\% de catalisador em relação à massa de óleo, razão molar $(\mathrm{RM})$ metanol:óleo de $15: 1$ e $170{ }^{\circ} \mathrm{C}$ por $8 \mathrm{~h}$, uma conversão de $98,3 \%$ em monoésteres foi obtida. Após a reação, testes de estabilidade do catalisador foram realizados com base na sua recuperação do meio por centrifugação e subsequente reutilização em um novo ciclo catalítico sem nenhuma etapa de lavagem ou purificação. Os experimentos não revelaram redução na atividade catalítica, que forneceu conversões de $98,0 \%$ no primeiro, $97,9 \%$ no segundo e $98,1 \%$ no terceiro ciclo.

A solubilização do catalisador também foi avaliada pelo seu aquecimento em metanol por $2 \mathrm{~h}$ nas mesmas condições de reação, porém, na ausência do óleo vegetal, com posterior filtração a quente. $\mathrm{O}$ filtrado foi adicionado ao óleo de girassol e deixado por $6 \mathrm{~h}$ nas mesmas condições anteriormente testadas com o catalisador sólido. Após este período, não foi constatada conversão do óleo de girassol em monoésteres alquílicos, o que pode demonstrar que não houve lixiviação de espécies cataliticamente ativas para o meio de reação. No entanto, nenhuma iniciativa de caracterização foi realizada no sólido recuperado após a reação. ${ }^{13}$

A transesterificação do óleo de soja foi realizada com zircônia sulfatada $\left(\mathrm{ZrO}_{2} / \mathrm{SO}_{4}{ }^{2-}\right)$ empregando RM álcool:óleo de 20:1 e 5\% de catalisador a $120^{\circ} \mathrm{C}$ por $1 \mathrm{~h}$. Nestas condições, conversões de 98,6 e 92,0\% foram obtidas na metanólise e na etanólise, respectivamente. ${ }^{14}$ Porém, em testes de reutilização nas reações de metanólise, o catalisador foi rapidamente desativado, apresentando conversões de $59 \%$ na segunda, $30 \%$ na terceira e $14 \%$ após a quarta etapa de reuso.

Após o primeiro ciclo de reação, o catalisador foi filtrado, lavado com hexano e seco a $60{ }^{\circ} \mathrm{C}$ durante $1 \mathrm{~h}$. Uma amostra deste sólido foi agitada em água por $24 \mathrm{~h}$, com posterior filtração e tratamento do filtrado com solução de cloreto de bário, a fim de verificar a lixiviação dos ânions sulfato para o meio de reação. O mesmo procedimento também foi realizado com uma amostra do sólido de origem, ainda não utilizado na transesterificação. Em ambos os casos, a lixiviação de íons $\mathrm{SO}_{4}^{-2}$ foi confirmada pela formação de um precipitado branco de $\mathrm{BaSO}_{4}$, evidenciando que o catalisador perde a sua principal espécie catalítica durante a reação e que os resultados obtidos foram majoritariamente devidos à catálise ácida em meio homogêneo. ${ }^{14}$

Cordeiro e colaboradores utilizaram hidroxinitrato de zinco (HNZ) como catalisador em reações de esterificação metílica e etílica do ácido láurico e de metanólise do óleo de palma refinado. ${ }^{8}$ Conversões de $97,4 \%$ do ácido láurico em laurato de metila foram obtidas em reator pressurizado a $140{ }^{\circ} \mathrm{C}$ por $2 \mathrm{~h}$, empregando $\mathrm{RM}$ metanol:ácido de 4:1 e 4\% de catalisador. Quando foi utilizado etanol nas condições de RM de $6: 1$ e $2 \%$ de catalisador a $140{ }^{\circ} \mathrm{C}$ por $2 \mathrm{~h}$, conversões em monoésteres etílicos de $77,2 \%$ foram obtidas.

Após as reações, o catalisador foi recuperado e caracterizado por difração de raios X de pó (DRX) e por espectroscopia vibracional no infravermelho com transformada de Fourier (IVTF), sendo constatada a transformação in situ do HNZ em carboxilato de zinco, ao qual foi atribuída a atividade catalítica observada. Para confirmar esta hipótese, o laurato de zinco foi sintetizado externamente ao meio de reação e sua atividade catalítica foi demonstrada na esterificação metílica e etílica do ácido láurico, empregando as mesmas condições de reação citadas acima.

O óxido de cálcio foi utilizado para catalisar a metanólise do óleo de pinhão manso, sob RM metanol:óleo de 9:1, 1,5\% de catalisador a $64,7^{\circ} \mathrm{C}$ por $2,5 \mathrm{~h}$. Nestas condições, uma conversão em monoésteres metílicos de $93 \%$ foi obtida. ${ }^{15}$ Porém, os produtos da reação apresentaram uma alta concentração de cálcio $(1,2 \mathrm{mg} \mathrm{mL}$ ${ }^{1}$ ), indicando que a espécie catalítica foi parcialmente lixiviada do material de origem. Estudos posteriores utilizando difratometria de raios X para caracterizar este mesmo catalisador $(\mathrm{CaO})$, antes e após a transesterificação do óleo de colza, forneceram evidências de que o óxido de cálcio foi parcialmente transformado em metóxido de cálcio, sendo esta a espécie responsável pela atividade catalítica observada. ${ }^{10}$

Após impregnação com hidróxido de potássio, zeólitas do tipo $\mathrm{NaX}$ com relação molar $\mathrm{Si} / \mathrm{Al}$ de 1,23 foram utilizadas como catalisadores da metanólise do óleo de soja. ${ }^{16}$ Os melhores resultados foram obtidos quando o percentual de $\mathrm{KOH}$ impregnado foi de $10 \%$ e o material foi pré-aquecido a $120^{\circ} \mathrm{C}$ por $3 \mathrm{~h}$. Quando a metanólise foi efetuada com $3 \%$ de catalisador a $64,7^{\circ} \mathrm{C}$, RM álcool:óleo de 10:1 e refluxo por $8 \mathrm{~h}$, o rendimento foi de $85,6 \%$. Na tentativa de reutilização do catalisador, rendimentos de apenas $48,7 \%$ foram obtidos nas mesmas condições experimentais. Tal comportamento foi provavelmente devido à lixiviação de $\mathrm{KOH}$ para o meio de reação, o que resultou em um processo homogêneo de conversão baseado na formação de metóxido de potássio a partir de sua reação com o metanol.

A hidrotalcita $\mathrm{Mg}_{6} \mathrm{Al}_{2}(\mathrm{OH})_{16} \mathrm{CO}_{3} \cdot 4 \mathrm{H}_{2} \mathrm{O}$ foi utilizada para a metanólise da gordura de frango após calcinação por $8 \mathrm{~h}$ sob fluxo de $\mathrm{N}_{2}$, em temperaturas que variaram entre 400 a $800{ }^{\circ} \mathrm{C} .{ }^{17} \mathrm{O}$ melhor rendimento $(94 \%)$ foi obtido ao se utilizar $10 \%$ do catalisador calcinado a $500{ }^{\circ} \mathrm{C}$ em RM metanol:gordura de frango de $60: 1$ a $120^{\circ} \mathrm{C}$ por $6 \mathrm{~h}$. Etapas posteriores de reutilização foram realizadas e o sólido manteve a sua atividade, sem quaisquer evidências de lixiviação da espécie catalítica.

Diferentemente de muitos metais pesados, o bismuto é um metal não corrosivo que apresenta baixa toxicidade e grande facilidade no manuseio. Além disso, compostos de bismuto exibem acidez de Lewis de moderada a forte devido à blindagem deficiente do núcleo pelos elétrons $\mathrm{f}$ do átomo de bismuto $\left(\mathrm{Bi}=[\mathrm{Xe}] 4 \mathrm{f}^{14}, 5 \mathrm{~d}^{10}, 6 \mathrm{~s}^{2}, 6 \mathrm{p}^{3}\right) .^{18-24}$ Por consequência, o comportamento catalítico destes compostos tem sido investigado em diferentes tipos de reações químicas, exceto em reações de transesterificação, onde sua aplicação catalítica ainda é desconhecida. Por outro lado, o sólido $\mathrm{NaBiO}_{3} \cdot 2 \mathrm{H}_{2} \mathrm{O}$ também é frequentemente utilizado na determinação de manganês em ferro e aço. ${ }^{25,26}$

No presente trabalho, a atividade catalítica de compostos de bismuto foi investigada em reações de transesterificação metílica do óleo de soja. Esta investigação foi então aprofundada pelo uso de métodos analíticos complementares para avaliar o caráter heterogêneo da reação, por meio da caracterização do sólido antes e após as reações e da extensão com que espécies catalíticas foram eventualmente lixiviadas.

\section{PARTE EXPERIMENTAL}

$\mathrm{O} \mathrm{NaBiO} \cdot 2 \mathrm{H}_{2} \mathrm{O}$ comercial, sem qualquer tratamento térmico, foi submetido à análise térmica (análise termogravimétrica e análise térmica diferencial, TGA/DTA) em um equipamento TA Instruments, modelo SDT Q 600. Tais análises foram realizadas de 25 a $1000^{\circ} \mathrm{C}$ a $20{ }^{\circ} \mathrm{C} \mathrm{min}{ }^{-1}$, sob atmosfera de $\mathrm{N}_{2}$ em uma vazão de $100 \mathrm{~mL} \cdot \mathrm{min}^{-1}$.

Os compostos sólidos contendo bismuto, tratados ou não termicamente, foram estudados como possíveis catalisadores para a transesterificação metílica de óleo de soja refinado (Liza ${ }^{\circledR}$, Cargill, Mairinque, SP). Foram eles: bismutato de sódio di-hidratado $\left(\mathrm{NaBiO}_{3} \cdot 2 \mathrm{H}_{2} \mathrm{O}\right.$ P.A. 99,9\%, Riedel-de Haën ${ }^{\circledR}$, Seelze, Alemanha), sem qualquer prétratamento; $\mathrm{NaBiO}_{3} \cdot 2 \mathrm{H}_{2} \mathrm{O}$ comercial tratado a $280^{\circ} \mathrm{C}$ por $3 \mathrm{~h}$ em mufla sob atmosfera ambiente, resultando em um sólido de cor marrom; $\mathrm{NaBiO}_{3} \cdot 2 \mathrm{H}_{2} \mathrm{O}$ comercial tratado a $500{ }^{\circ} \mathrm{C}$ durante $2 \mathrm{~h}$ em mufla sob 
atmosfera ambiente, resultando em um sólido de cor amarela e, óxido de bismuto na sua forma comercial $\left(\mathrm{Bi}_{2} \mathrm{O}_{3}\right.$ P.A. mín. $98,0 \%$, Vetec ${ }^{\circledR}$, Duque de Caxias, RJ), sem qualquer tratamento prévio.

Para confirmação das análises de TGA/DTA, todos os sólidos envolvidos neste estudo foram caracterizados por DRX, utilizando-se um difratômetro Shimadzu ${ }^{\circledR}$ XRD-6000 em modo de reflexão, com radiação $\mathrm{CuK}_{\alpha}(40 \mathrm{kV}$ e $30 \mathrm{~mA})$ de $0,15418 \mathrm{~nm}(\lambda)$ no intervalo de $3 \mathrm{a}$ $60^{\circ}$ de $2 \theta$, com passo de $0,04^{\circ}$ e velocidade de varredura de $2^{\circ} \mathrm{min}^{-1}$.

Os testes de atividade catalítica foram realizados em balão de vidro de fundo redondo, onde se pesou o óleo vegetal, adicionandose em seguida o volume de metanol $\left(\mathrm{CH}_{3} \mathrm{OH}\right.$ P.A. $99,8 \% \operatorname{com} 0,1 \%$ de umidade, Vetec ${ }^{\circledR}$, Diadema, SP) na proporção molar desejada em relação ao óleo. Considerou-se a massa molar média do óleo de soja como sendo equivalente à da trioleína, ou seja, 884,70 $\mathrm{g} \mathrm{mol}^{-1} .^{27} \mathrm{O}$ sólido (5\% em relação à massa de óleo) foi adicionado e o sistema foi mantido sob agitação magnética de $1200 \mathrm{rpm}$ por 1 a $3 \mathrm{~h}$, em aquecimento sob refluxo de metanol $\left(64,7^{\circ} \mathrm{C}\right)$.

Após a reação, os produtos foram separados por centrifugação a $3500 \mathrm{rpm}$ por 5 min e o excesso de álcool foi evaporado a $50^{\circ} \mathrm{C}$ em evaporador rotativo sob pressão reduzida. Após evaporação do excesso de álcool e centrifugação, pôde-se perceber a presença de três fases distintas: a fase sólida depositada no fundo do frasco, a fração rica em glicerol e a fração rica em monoésteres graxos, que foram separados e analisados.

Para os ensaios de solubilidade do catalisador em metanol, adicionaram-se $2,01 \mathrm{~g} \mathrm{de} \mathrm{NaBiO}_{3} \cdot 2 \mathrm{H}_{2} \mathrm{O}$ sem qualquer tratamento prévio em $22,3 \mathrm{~mL}$ de metanol e a mistura permaneceu em aquecimento sob refluxo por $1 \mathrm{~h}$ a $1200 \mathrm{rpm}$. A suspensão foi centrifugada a 3500 rpm por 10 min e, em seguida, o sobrenadante foi filtrado a vácuo em filtro Duran 50 e, então, evaporado a $100{ }^{\circ} \mathrm{C}$ por 10 min para total eliminação do solvente, recuperando-se $65,8 \mathrm{mg}$ de material sólido solúvel em metanol. A atividade catalítica deste material foi avaliada utilizando $0,7 \%$ de sólido em relação à massa de óleo empregada na reação (18,0 mg para 2,55 g de óleo) e 1,39 mL de metanol para perfazer uma RM metanol:óleo de 12:1. O experimento foi conduzido em aquecimento sob refluxo por $1 \mathrm{~h}$ e agitação de $1200 \mathrm{rpm}$.

$\mathrm{O}$ restante do material resultante da solubilização parcial do catalisador (47,8 mg) foi tratado com $5 \mathrm{~mL}$ de $\mathrm{HNO}_{3} 10 \%$ (v/v) e aquecimento brando até sua completa dissolução. $\mathrm{O}$ volume da solução foi aferido em balão volumétrico de $25 \mathrm{~mL}$ com água deionizada e analisada por emissão óptica com plasma indutivamente acoplado em configuração axial (ICP-OES) em espectrômetro Varian ${ }^{\circledR}$ Vista Pro, empregando argônio de 99,99\% de pureza. A curva de calibração foi preparada a partir de um branco e de soluções padrão de Na e Bi. As intensidades de emissão foram obtidas nas linhas analíticas de maior sensibilidade, livres de interferentes, em 589 e $592 \mathrm{~nm}$ para o sódio e em 223,06 nm para o bismuto. A determinação quantitativa dos sinais foi baseada na altura dos picos em relação a uma série de padrões verdadeiros. ${ }^{28}$

A avaliação da concentração do elemento sódio em amostras de $\mathrm{NaBiO}_{3} \cdot 2 \mathrm{H}_{2} \mathrm{O}$, antes e após as reações de metanólise, foi realizada em fotômetro de chama Digimed ${ }^{\circledR}$ DM-61 com resolução de $0,1 \mathrm{mg}$ $\mathrm{L}^{-1}$, operando com gás liquefeito de petróleo na pressão de 0,7 bar para geração da chama. Após ter sido realizada uma reação sob RM metanol:óleo de 30:1, 5\% de catalisador, $1200 \mathrm{rpm}$ a $64,7^{\circ} \mathrm{C}$ por $3 \mathrm{~h}$ (reação 1), uma amostra de sólido foi lavada com etanol absoluto:hexano $1: 1(\mathrm{v} / \mathrm{v})$ sob agitação por 3 vezes de $30 \mathrm{~min}$ e depois seca em estufa a $65{ }^{\circ} \mathrm{C}$ por $24 \mathrm{~h}$ antes do procedimento de análise. Foram preparadas duas soluções de análise, uma a partir da pesagem de $14,2 \mathrm{mg}$ de $\mathrm{NaBiO}_{3} \cdot 2 \mathrm{H}_{2} \mathrm{O}$ (que não foi utilizado em catálise e que teoricamente deveria conter uma concentração de sódio de $20 \mathrm{mg} \cdot \mathrm{L}^{-1}$ ), denominada solução 1 , e outra com 14,7 mg deste mesmo sal após um ciclo de reação (solução 2). O objetivo deste experimento foi determinar o conteúdo de sódio restante no $\mathrm{NaBiO}_{3} \cdot 2 \mathrm{H}_{2} \mathrm{O}$ após a reação.

A análise prévia dos produtos das reações foi realizada de forma qualitativa por cromatografia de camada delgada (CCD), utilizando-se como eluente uma mistura 9:1 de éter de petróleo:éter etílico (ambos da Labsynth ${ }^{\circledR}$ ) em cromatoplacas AL TLC de sílica gel 60 (Merck $\left.{ }^{\circledR}\right)$, reveladas com iodo sublimado. Para comparação com os monoésteres produzidos nas reações, foram utilizados como padrões o óleo de soja refinado e os monoésteres metílicos dele derivados.

As determinações qualitativas e quantitativas dos monoésteres metílicos produzidos foram realizadas por cromatografia a líquido com fase reversa quimicamente ligada (CLAE-C18), empregando sistema Shimadzu ${ }^{\circledR}$ LC10AD com coluna Spherisorb-C18 (4,6 x 250 $\mathrm{mm}, 5 \mu \mathrm{m})$, mantida a $40{ }^{\circ} \mathrm{C}$ e eluída com acetonitrila:acetona (9:1 v/v, Carlo Erba ${ }^{\circledR}$ ) em eluição isocrática a $0,9 \mathrm{~mL} \mathrm{~min}^{-1}$. As curvas de calibração do sistema foram realizadas por padronização externa, utilizando-se padrões verdadeiros dos monoésteres metílicos dos ácidos linolênico, linoleico, oleico, palmítico e esteárico. Os dados cromatográficos obtidos foram tratados pelo programa CLASS 10 da Shimadzu ${ }^{\circledR}$.

As análises por cromatografia de permeação em gel (CPG) foram obtidas em sistema Shimadzu ${ }^{\circledR}$ LC10AD mediante o emprego de duas colunas TSK Gel (HXL 2000 e 1000) em série, cujos limites de exclusão corresponderam a $4 \times 10^{5}$ e $10^{3}$ u.m.a., respectivamente. As análises foram realizadas a $45{ }^{\circ} \mathrm{C}$ utilizando tetra-hidrofurano (J. T. Baker ${ }^{\circledR}$ ) como fase móvel, a uma vazão de 1,0 $\mathrm{mL} \mathrm{min}{ }^{-1}$. A análise quantitativa dos componentes foi realizada por padronização externa, com base em soluções-padrão de trioleína (1,2,3-tri-[(cis)9-octadecenoil]-glicerol), dioleína (1,3-di-[(cis)-9-octadecenoil]glicerol), mono-oleína (1-mono-[( cis)-9-octadecenoil]-rac-glicerol) e oleato de etila, todos adquiridos da Sigma-Aldrich ${ }^{\circledR}$ (St. Louis, MO). Estes padrões foram empregados como modelos para a análise de triacilgliceróis, diacilgliceróis, monoacilgliceróis e monoésteres metílicos, respectivamente.

\section{RESULTADOS E DISCUSSÃO}

As curvas de TGA/DTA do $\mathrm{NaBiO}_{3} \cdot 2 \mathrm{H}_{2} \mathrm{O}$ apresentaram vários eventos térmicos no decorrer da análise e uma perda de massa de $10,5 \%$ até $300^{\circ} \mathrm{C}$, o que corresponde à perda das moléculas de água em um valor aproximado de $11,4 \%$. Essa perda de massa esteve associada a um pico de natureza endotérmica, centrado em $143{ }^{\circ} \mathrm{C}$ (Figura 1).

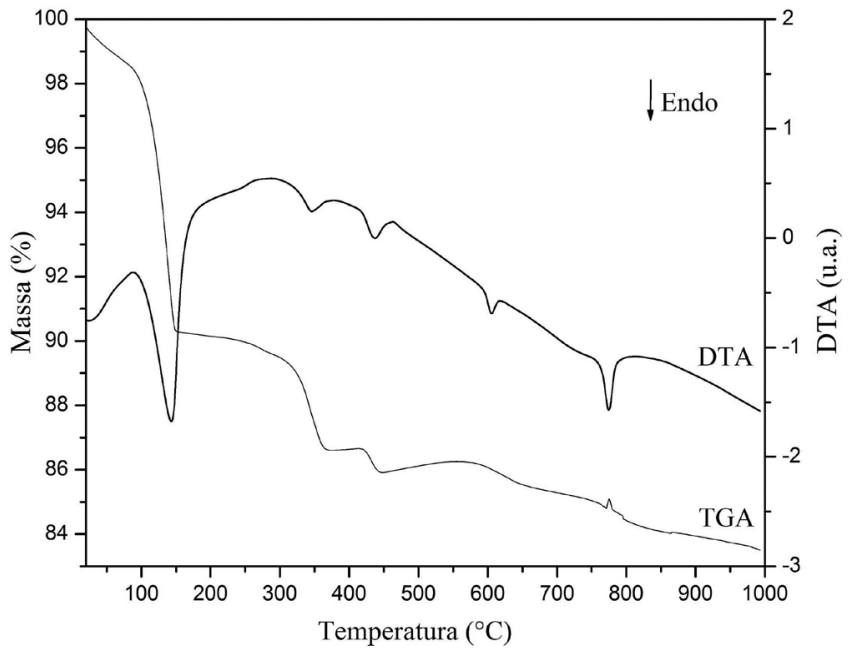

Figura 1. Curvas de análise térmica (TGA/DTA) do bismutato de sódio comercial 
O evento endotérmico presente em $332{ }^{\circ} \mathrm{C}$ na curva de DTA foi associado a uma perda de massa de 2,97\%. Esta perda foi atribuída à decomposição do $\mathrm{NaBiO}_{3}$ em $\mathrm{Na}_{2} \mathrm{O}$ amorfo e óxido de bismuto, na forma de $\delta-\mathrm{Bi}_{2} \mathrm{O}_{3,33}$, eliminando $\mathrm{O}_{2}$ no processo. ${ }^{29} \mathrm{Em} 437{ }^{\circ} \mathrm{C}$, outro evento endotérmico indica a conversão do $\delta-\mathrm{Bi}_{2} \mathrm{O}_{3,33}$ em $\alpha-\mathrm{Bi}_{2} \mathrm{O}_{3}$, juntamente a uma nova eliminação de $\mathrm{O}_{2}$ e este processo correspondeu a uma perda de massa de $0,65 \%$. O evento em $463{ }^{\circ} \mathrm{C}$ foi caracterizado pela cristalização do $\mathrm{Na}_{2} \mathrm{O}$, enquanto que a $606^{\circ} \mathrm{C}$ houve a formação de uma fase líquida como resultado da fusão do eutético, que permaneceu no sistema em temperaturas superiores a $774{ }^{\circ} \mathrm{C}$. A perda de massa de $16,5 \%$ a $1000{ }^{\circ} \mathrm{C}$ corresponde à decomposição do material em $\mathrm{Bi}_{2} \mathrm{O}_{3}$ e $\mathrm{Na}_{2} \mathrm{O}$. Portanto, os dados de análise térmica comprovaram a pureza do material utilizado nas reações.

Os difratogramas de raios X, presentes na Figura 2, confirmaram as observações decorrentes da análise térmica (TGA/DTA), demonstrando que, durante o tratamento térmico, o $\mathrm{NaBiO}_{3} \cdot 2 \mathrm{H}_{2} \mathrm{O}$ se decompôs em uma mistura de óxidos $\left(\mathrm{Bi}_{2} \mathrm{O}_{3} / \mathrm{Na}_{2} \mathrm{O}\right)$.

$\mathrm{O} \mathrm{NaBiO} \cdot 2 \mathrm{H}_{2} \mathrm{O}$ comercial (Figura $2 \mathrm{a}$ ) e as espécies derivadas de seu tratamento térmico (Figuras $2 \mathrm{~b}$ e $2 \mathrm{c}$ ), juntamente com o $\mathrm{Bi}_{2} \mathrm{O}_{3}$ (Figura 2d), tiveram seus picos de difração indexados de acordo com o banco de dados do Centro Internacional para Dados de Difração (JCPDS). Na Figura 2a, somente cinco picos de difração, situados em 37,$07 ; 56,08 ; 57,13 ; 58,52$ e $59,76^{\circ}$ de $2 \theta$, não puderam ser atribuídos à estrutura do $\mathrm{NaBiO}_{3} \cdot 2 \mathrm{H}_{2} \mathrm{O} \cdot{ }^{30}$

O difratograma do $\mathrm{NaBiO}_{3} \cdot 2 \mathrm{H}_{2} \mathrm{O}$, após tratamento a $280{ }^{\circ} \mathrm{C}$ por $3 \mathrm{~h}$ (Figura 2b), apresentou os picos de difração esperados para o composto anidro. No entanto, o pico alargado em $30,46^{\circ}$ de $2 \theta$ foi atribuído ao halo amorfo de sílica, oriundo do porta-amostras de vidro, enquanto que os picos de difração em 52,53; 55,56 e 57,46 ${ }^{\circ}$ de $2 \theta$ não puderam ser associados à estrutura do $\mathrm{NaBiO}_{3} \cdot{ }^{31} \mathrm{O}$ tratamento térmico do $\mathrm{NaBiO}_{3} \cdot 2 \mathrm{H}_{2} \mathrm{O}$ por $2 \mathrm{~h}$ a $500{ }^{\circ} \mathrm{C}$ (Figura $2 \mathrm{c}$ ) resultou em um composto cujos picos de difração foram equivalentes aos picos de difração do $\mathrm{Bi}_{2} \mathrm{O}_{3}$ (Figura 2d) e do $\mathrm{Na}_{2} \mathrm{O}$, comprovando a já mencionada formação de um óxido misto. ${ }^{32-34}$

Os experimentos de transesterificação metílica do óleo de soja foram inicialmente realizados para investigar o efeito da RM metanol:óleo, do tempo de reação e da espécie catalítica utilizada sobre o rendimento das reações. Os resultados gerados, empregandose 3 das 4 espécies testadas, encontram-se na Tabela 1.

Os monoésteres produzidos em todas as reações foram analisados previamente por CCD, não sendo observada a presença de triacilgliceróis não convertidos ou de produtos de conversão parcial (di- e monoacilgliceróis), sugerindo, portanto, uma alta conversão

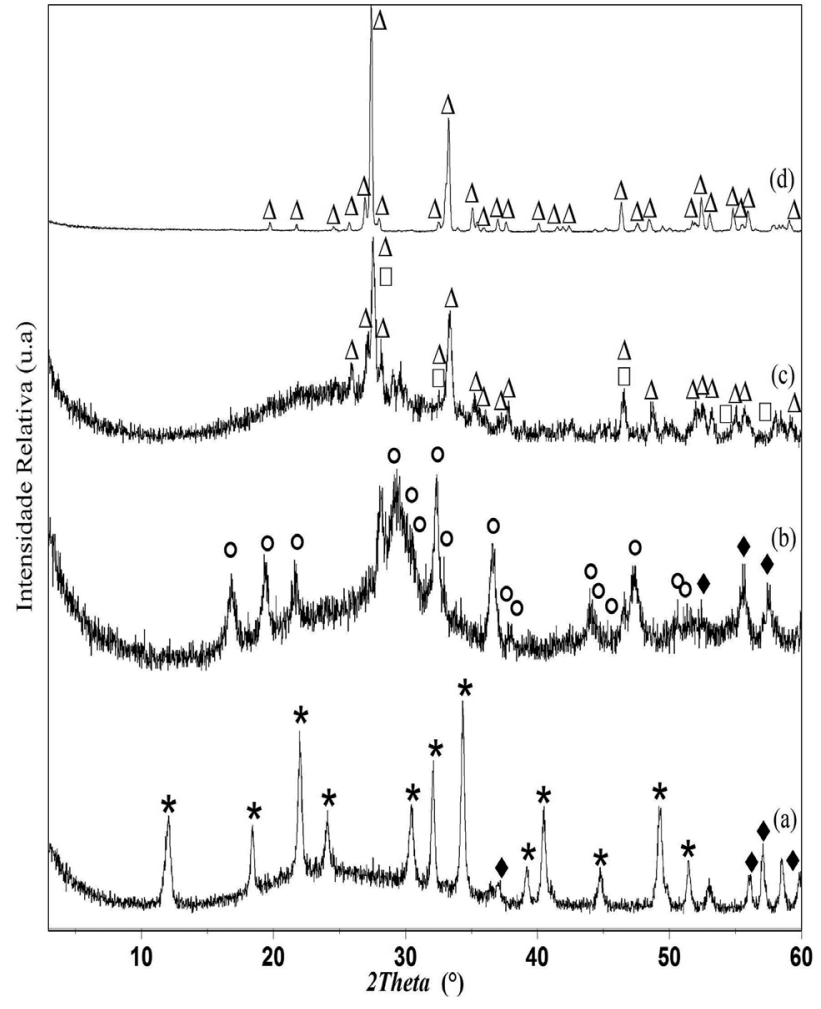

Figura 2. Difratogramas de raios $X$ das quatro espécies investigadas: (a) $\mathrm{NaBiO}_{3} \cdot 2 \mathrm{H}_{2} \mathrm{O}$ sem tratamento térmico, (b) $\mathrm{NaBiO}_{3} \cdot 2 \mathrm{H}_{2} \mathrm{O}$ tratado a $280^{\circ} \mathrm{C} / 3$ h, (c) $\mathrm{NaBiO}_{3} \cdot 2 \mathrm{H}_{2} \mathrm{O}$ tratado a $500{ }^{\circ} \mathrm{C} / 2 \mathrm{~h}$, (d) $\mathrm{Bi}_{2} \mathrm{O}_{3}$ sem tratamento térmico. Os picos de difração do $\mathrm{NaBiO}_{3} \cdot 2 \mathrm{H}_{2} \mathrm{O}$ ( JCPDS $\left.n^{\circ} 110005\right)$ foram identificados com asteriscos; os do $\mathrm{NaBiO}_{3}\left(\mathrm{JCPDS} n^{\circ} 110006\right)$, com círculos abertos; os do $\mathrm{Na}_{2} \mathrm{O}$ (JCPDS $n^{\circ}$ 031074), com quadrados abertos; os do $\mathrm{Bi}_{2} \mathrm{O}_{3}$ (JCPDS $n^{\circ} 720398$ ), com triângulos abertos e os losangos fechados revelam picos que não puderam ser identificados. Adaptados das refs. 30-34

do material graxo em monoésteres alquílicos. A análise por CLAE-C18, empregando o método de padronização externa, revelou que, independentemente da espécie catalítica utilizada, teores de monoésteres metílicos superiores a $88 \%$ foram obtidos, sendo observados somente os picos referentes aos principais monoésteres esperados da metanólise do óleo de soja (linolenato, linoleato, oleato, palmitato e estearato de metila). Além disto, rendimentos em monoésteres acima

Tabela 1. Resultados obtidos na metanólise do óleo de soja utilizando como catalisadores diferentes compostos de bismuto*

\begin{tabular}{|c|c|c|c|c|c|}
\hline Razão molar MeOH:Óleo & Tempo (h) & Massa de óleo (g) & Massa de éster (g) & Teor de éster $(\%)$ & Rendimento $(\%)$ \\
\hline \multicolumn{6}{|c|}{ Bismutato de sódio comercial $\left(\mathrm{NaBiO}_{3} \cdot 2 \mathrm{H}_{2} \mathrm{O}\right)$} \\
\hline $54: 1$ & 3,0 & 9,37 & 8,29 & 97,21 & 85,65 \\
\hline $30: 1$ & 3,0 & 9,07 & 8,37 & 90,68 & 83,28 \\
\hline $21: 1$ & 2,0 & 10,81 & 10,08 & 90,22 & 83,80 \\
\hline $12: 1$ & 1,0 & 7,68 & 7,09 & 90,06 & 82,83 \\
\hline \multicolumn{6}{|c|}{ Sólido tratado a $280{ }^{\circ} \mathrm{C}$ por $3 \mathrm{~h}\left(\mathrm{NaBiO}_{3}\right)$} \\
\hline $54: 1$ & 3,0 & 9,06 & 7,81 & 88,84 & 76,18 \\
\hline $30: 1$ & 3,0 & 9,24 & 7,58 & 93,52 & 76,37 \\
\hline $12: 1$ & 1,0 & 7,27 & 6,98 & 91,94 & 87,84 \\
\hline \multicolumn{6}{|c|}{ Sólido tratado a $500{ }^{\circ} \mathrm{C}$ por $2 \mathrm{~h}$} \\
\hline $54: 1$ & 3,0 & 9,06 & 8,40 & 93,16 & 85,93 \\
\hline $21: 1$ & 3,0 & 9,54 & 8,94 & 89,28 & 83,24 \\
\hline $12: 1$ & 3,0 & 10,23 & 8,90 & 93,33 & 80,87 \\
\hline $12: 1$ & 1,0 & 7,16 & 6,12 & 92,04 & 78,32 \\
\hline
\end{tabular}

${ }^{*}$ Todos os experimentos foram realizados a $64,7^{\circ} \mathrm{C}$ (temperatura de ebulição do metanol) para evitar problemas difusionais, ${ }^{12}$ empregando $5 \%$ de sólido em relação à massa de óleo utilizada na reação. 
de $76 \%$ foram obtidos em todas as reações, independente do sólido investigado, o que foi considerado importante enquanto indicador quantitativo da atividade catalítica observada. Estas taxas de conversão, obtidas em condições brandas de reação, seriam provavelmente maiores caso os procedimentos experimentais tivessem sido otimizados. Porém, em todas as condições avaliadas, foi observado que a glicerina produzida apresentava cor marrom escura e aspecto físico típico da glicerina obtida em processos convencionais de catálise em meio homogêneo, que é resultante de sua contaminação com sabões, álcool, água e catalisador residual. ${ }^{2}$

De fato, o aspecto das amostras de glicerina obtidas nas reações, utilizando qualquer um dos três sólidos estudados $\left(\mathrm{NaBiO}_{3} \cdot 2 \mathrm{H}_{2} \mathrm{O}\right.$ comercial ou tratado termicamente a 280 ou $500{ }^{\circ} \mathrm{C}$ ), foi muito diferente do aspecto incolor que se esperava de processos puramente heterogêneos. ${ }^{8}$ Esta observação experimental sugeriu que os sólidos investigados como catalisadores heterogêneos poderiam estar sofrendo modificação química ou solubilização parcial no meio de reação, resultando na liberação de espécies solúveis que poderiam promover fenômenos de catálise homogênea. A fim de investigar esta hipótese, ensaios complementares de ICP-OES, fotometria de chama e CPG foram realizados.

A determinação da solubilização do $\mathrm{NaBiO}_{3} \cdot 2 \mathrm{H}_{2} \mathrm{O}$ comercial em metanol foi realizada por meio do seu tratamento nas mesmas condições de reações testadas anteriormente, porém, com a omissão do óleo de soja, que resultou na obtenção de $65,8 \mathrm{mg}$ de um sólido branco, diferente da cor amarelo-pálida do sal de bismuto de origem, que correspondeu a 2,38\% da massa inicial de sal utilizado.

A análise por ICP-OES da fração solúvel em metanol (sólido branco) demonstrou a presença de $15,90 \%(\mathrm{~m} / \mathrm{m})$ de sódio e apenas $0,46 \%(\mathrm{~m} / \mathrm{m})$ de bismuto, ou seja, uma concentração de sódio 34,5 vezes maior do que a de bismuto. A atividade catalítica deste sólido branco também foi avaliada empregando $0,7 \%(\mathrm{~m} / \mathrm{m})$ em relação ao óleo, de modo a permitir uma comparação direta com processos convencionais de produção de biodiesel, onde se empregam hidróxidos como precursores de catálise ou alcóxidos (metóxido) de sódio ou potássio na faixa de 0,5 a 1,0\%, dependendo das condições de reação e da acidez das matérias-primas..$^{35,36}$

Nos experimentos realizados com este material, sob RM metanol:óleo de $12: 1,1200 \mathrm{rpm}$ a $64,7^{\circ} \mathrm{C}$ por $1 \mathrm{~h}$, nenhum material insolúvel foi observado no meio de reação, evidenciando que o sólido branco tinha sido totalmente solubilizado. Além disso, houve a formação de duas fases líquidas imiscíveis, uma inferior, aparentemente constituída de glicerina, e uma superior, que foi coletada e analisada por CPG. Novamente, a fase rica em glicerol apresentou o aspecto típico dos produtos de reação de transesterificação de óleos vegetais em meio homogêneo alcalino.

A análise por CPG da fase superior revelou que esta era constituída de $23,6 \%$ de trioleína, $10,7 \%$ de dioleína, 3,3\% de monoleína e $62,3 \%$ de oleato de metila. A partir destes resultados, pode-se afirmar que o sólido branco, obtido como espécie solúvel em metanol quando o bismutato de sódio foi tratado com este solvente, era cataliticamente ativo e que, nas condições típicas de transesterificação em meio homogêneo, promoveu uma conversão de mais de $62 \%$ do óleo de soja em monoésteres alquílicos. Além deste estudo, o sólido amarelo, resultante da remoção da fração solúvel em metanol, foi avaliado nas mesmas condições experimentais utilizadas para o sólido branco (RM de 12:1, 64,7 ${ }^{\circ} \mathrm{C}, 1150 \mathrm{rpm}$ por $1 \mathrm{~h}$ ). As análises de CCD e CPG demonstraram uma conversão praticamente desprezível do óleo de soja em monoésteres de alquila. Portanto, estes resultados permitem concluir que o bismutato de sódio, quando exposto ao meio metanólico nas condições de reação empregadas neste estudo, sofre decomposição parcial a $\mathrm{Na}_{2} \mathrm{O}$ que é parcialmente lixiviado do sal de origem, para depois reagir com moléculas de água presentes no meio de reação gerando $\mathrm{NaOH}$. Em etapa subsequente, este $\mathrm{NaOH}$ reage com o metanol adicionado em excesso, gerando $\mathrm{NaCH}_{3} \mathrm{O}$ (metóxido de sódio) e água. Assim, a água é regenerada ao final do processo, realimentando o ciclo de conversão do $\mathrm{Na}_{2} \mathrm{O}$ em metóxido de sódio, em um processo contínuo que leva à total remoção do sódio presente no sal de origem. Alternativamente, o $\mathrm{Na}_{2} \mathrm{O}$ pode reagir diretamente com o $\mathrm{MeOH}$, também gerando $\mathrm{NaCH}_{3} \mathrm{O}$. Portanto, estes dados comprovam que o processo catalítico ocorre essencialmente em meio homogêneo, e não heterogêneo como inicialmente proposto, uma vez que o agente catalítico é o $\mathrm{NaCH}_{3} \mathrm{O}$. Seguindo esta mesma linha de raciocínio, um trabalho publicado recentemente, ao relatar a utilização de $\mathrm{SrO}$ e $\mathrm{CaO}$ para a metanólise do óleo de colza, demonstra que os óxidos foram lixiviados durante o processo, sendo transformados em seus respectivos metóxidos, aos quais foi atribuída a atividade catalítica observada. ${ }^{10}$

A fim de fornecer maiores informações sobre o comportamento dos compostos de bismuto nesta reação, o sólido recuperado como insolúvel em metanol (sólido amarelo escuro) foi então submetido a um tratamento térmico a $280{ }^{\circ} \mathrm{C}$ por $3 \mathrm{~h}$ para posterior análise por DRX. Como resultado, foi obtido um padrão de difração semelhante ao esperado para o $\mathrm{Bi}_{2} \mathrm{O}_{3}$ (Figura 2d), muito diferente do perfil da espécie anidra $\left(\mathrm{NaBiO}_{3}\right)$ que seria formada quando o sal de partida $\left(\mathrm{NaBiO}_{3} 2 \mathrm{H}_{2} \mathrm{O}\right)$ sofre tratamento térmico sob estas condições. Portanto, estes resultados sugerem que o material insolúvel em metanol não apresenta quantidades significativas de sódio em sua composição química, o que estaria de acordo com o fato de que o sólido branco, solúvel em metanol, era composto majoritariamente por sódio, conforme demonstrado por ICP-OES.

Uma amostra de $\mathrm{Bi}_{2} \mathrm{O}_{3}$ comercial, sem qualquer tipo de pré-tratamento, foi também avaliada em condições análogas às empregadas anteriormente $\left(64,7^{\circ} \mathrm{C}\right.$ por $3 \mathrm{~h}$ em RM metanol:óleo de $54: 1$, $1200 \mathrm{rpm}$ e $5 \%$ de sólido) para elucidar se a atividade catalítica observada poderia ter sido decorrente deste óxido. No entanto, tal hipótese foi imediatamente descartada, pois a reação não forneceu nenhuma evidência de conversão do óleo de soja em monoésteres metílicos. O sólido recuperado após a reação foi então lavado com etanol:hexano $1: 1(\mathrm{v} / \mathrm{v})$ sob agitação por 3 vezes de $30 \mathrm{~min}$, seco em estufa a $65^{\circ} \mathrm{C}$ por $24 \mathrm{~h}$ e analisado por DRX. O difratograma resultante confirmou somente a presença de $\mathrm{Bi}_{2} \mathrm{O}_{3}$ (Figura 2d), revelando que o óxido não sofrera nenhuma modificação química durante o processo.

Considerando que o desempenho catalítico da espécie $\mathrm{Na}_{2} \mathrm{O} /$ $\mathrm{Bi}_{2} \mathrm{O}_{3}$ levou a teores de monoésteres (>93\%) e rendimentos $(>86 \%)$ (Tabela 1), muito próximos aos obtidos com $\mathrm{NaBiO}_{3} \cdot 2 \mathrm{H}_{2} \mathrm{O}$ e $\mathrm{NaBiO}_{3}$ anidro; que o $\mathrm{Bi}_{2} \mathrm{O}_{3}$ não apresentou nenhum desempenho catalítico mensurável e, que o sólido, após lavagem exaustiva com metanol, perdeu quase todo seu conteúdo de sódio e apresentou atividade catalítica praticamente desprezível, conclui-se que as taxas de conversão observadas na utilização do bismutato de sódio, na forma anidra ou di-hidratada, se devem também à formação de $\mathrm{Na}_{2} \mathrm{O}$, cuja presença foi constatada na fração solúvel em metanol na forma de metóxido de sódio. ${ }^{35,36}$

Finalmente, além das evidências já expostas, o sólido recuperado após reação nas condições de $64,7^{\circ} \mathrm{C}$ por $3 \mathrm{~h}$ em RM metanol:óleo de 54:1, $1200 \mathrm{rpm}$ e 5\% de sólido foi avaliado por fotometria de chama para caracterizar o seu conteúdo em sódio, empregando uma amostra de $\mathrm{NaBiO}_{3} \cdot 2 \mathrm{H}_{2} \mathrm{O}$ pura (contendo $20,3 \mathrm{mg} \mathrm{L}^{-1}$ de sódio) como controle. A amostra apresentou $0,8 \mathrm{mg} \mathrm{L}^{-1}$ de sódio, ou cerca de $4 \%$ do valor observado para uma amostra do sal antes da reação, confirmando que a lixiviação de $\mathrm{Na}_{2} \mathrm{O}$ ocorre quando o bismutato de sódio é utilizado como catalisador e que esta é a espécie precursora dos verdadeiros catalisadores da reação. 


\section{CONCLUSÃO}

O bismutato de sódio $\left(\mathrm{NaBiO}_{3} \cdot 2 \mathrm{H}_{2} \mathrm{O}\right)$, bem como os sólidos resultantes do seu aquecimento a $280^{\circ} \mathrm{C}\left(\mathrm{NaBiO}_{3}\right)$ ou a $500{ }^{\circ} \mathrm{C}\left(\mathrm{Bi}_{2} \mathrm{O}_{3} /\right.$ $\mathrm{Na}_{2} \mathrm{O}$ ), mostraram atividade catalítica em reações de transesterificação do óleo de soja. No entanto, a constatação da solubilização parcial dos sólidos no meio de reação levou à formação de espécies homogêneas cataliticamente ativas em reações de transesterificação.

A abordagem realizada neste estudo revela a necessidade de se conduzir uma investigação minuciosa sobre a real natureza da atividade de catalisadores sólidos estudados para produção de monoésteres alquílicos (biodiesel) em meio heterogêneo. Atualmente, poucos trabalhos relatam a utilização de métodos analíticos complementares para investigar a desativação de catalisadores aparentemente heterogêneos, ou mesmo para verificar se os processos catalíticos não estão associados a espécies facilmente lixiviáveis de sua estrutura química. Portanto, procedimentos como os realizados neste estudo se fazem necessários para evitar o erro de se atribuir resultados inicialmente promissores a processos heterogêneos, quando, na verdade, não passam de modelos convencionais baseados em catálise ácida ou alcalina em meio homogêneo.

\section{AGRADECIMENTOS}

À FINEP (Convênio 01.07.0480.00 - Ref. 3433/06) e ao CNPq (Processo 575812/2008-7) pelo aporte financeiro, ao Dr. E. J. dos Santos do Laboratório de Química Ambiental do Instituto de Tecnologia do Paraná (TECPAR) pela realização das análises de ICP-OES, e à Prof. ${ }^{a}$ Dr. ${ }^{a}$ K. J. Ciuffi da Universidade de Franca (UNIFRAN), pela realização da medida de análise térmica.

\section{REFERÊNCIAS}

1. Mathot, R. E. Em Manual de Biodiesel; Knothe, G.; Gerpen, J. V.; Krahl, J.; Ramos, L. P., eds.; Edgard Blücher: São Paulo, 2006, cap. 2.

2. Schuchardt, U.; Sercheli, R.; Vargas, R. M.; J. Braz. Chem. Soc. 1998, 9, 199.

3. Jordan, V.; Gutsche, B.; Chemosphere 2001, 43, 99.

4. Canacki, M.; Gerpen, J. V.; Trans. Am. Soc. Agric. Eng. 1999, 42, 1203.

5. Rinaldi, R.; Garcia, C.; Marciniuk, L. L.; Rossi, A. V.; Schuchardt, U.; Quim. Nova 2007, 30, 1374.

6. Suarez, P. A. Z.; Santos, A, L. F.; Rodrigues, J. P.; Alves, M. B.; Quim Nova 2009, 32, 768.

7. Gama, P. E.; Gil, R. A. S. S.; Lachter, E. R.; Quim. Nova 2010, 33, 1859.

8. Cordeiro, C. S.; Arizaga, G. G. C.; Ramos, L. P.; Wypych, F.; Catal. Commun. 2008, 9, 2140.

9. Wen, Z.; Yu, X.; Tu, S.; Yan, J.; Dahlquist, E.; Bioresour. Technol. 2010, 101,9570 .
10. Yoo, S. J.; Lee, H.-S.; Veriansyah, B.; Kim, J.; Kim, J.-D.; Lee, Y.-W.; Bioresour. Technol. 2010, 101, 8686.

11. Di Serio, M.; Tesser, R.; Pengmei, L.; Santacesaria, E.; Energy Fuels 2008, 22, 207.

12. Cordeiro, C. S.; Silva, F. R.; Wypych, F.; Ramos, L. P.; Quim. Nova 2011, 34, 477.

13. Sreeprasanth, P. S.; Srivastava, R.; Srinivas, D.; Ratnasamy, P.; Appl. Catal., A 2006, 314, 148.

14. Garcia, C. M.; Teixeira, S.; Marciniuk, L. L.; Schuchardt, U.; Bioresour. Technol. 2008, 99, 6608.

15. Huaping, Z.; Zongbin, W.; Yuanxiong, C.; Ping, Z.; Shijie, D.; Xiaohua, L.; Zongqiang, M.; Chin. J. Catal. 2006, 27, 391.

16. Xie, W.; Huang, X.; Li, H.; Bioresour. Technol. 2007, 98, 936.

17. Liu, Y.; Lotero, E.; Goodwin Jr., J. G.; Mo, X.; Appl. Catal., A 2007, $331,138$.

18. Leonard, N. M.; Wieland, L. C.; Mohan R S.; Tetrahedron 2002, 58, 8373.

19. Gaspard-Iloughmane, H.; Le Roux, C.; Eur. J. Org. Chem. 2004, 2517.

20. Ollevier, T.; Mwene-Mbeja, T. M.; Tetrahedron Lett. 2006, 47, 4051.

21. Lian, Y.; Hinkle, R. J.; J. Org. Chem. 2006, 71, 7071.

22. Qin, H.; Yamagiwa, N.; Matsunaga, S.; Shibasaki, M.; J. Am. Chem. Soc. 2006, 128, 1611.

23. Postel, M.; Dunach, E.; Coord. Chem. Rev. 1996, 155, 127.

24. Silvestru, C.; Chem. Rev. 1999, 99, 3277.

25. The Merck Index, $11^{\text {th }}$ ed., Merck: New Jersey, 1989.

26. Rigby, W. J.; J. Chem. Soc. 1950, 1907.

27. Byrdwell, W. C.; Neff, W. E.; J. Chromatogr., A 1999, 852, 417.

28. Santos, E. J.; Chaves, E. S.; Vechiatto, W. W. D.; Schoemberger, A. C.; Frescura, V. L. A.; Curtius, A. J.; J. Anal. At. Spectrom. 2007, 22, 1300 .

29. Murashov, V. A.; Rozantsev, A. V.; Klimenko, A. N.; Zharinova, T. A.; Russ. J. Inorg. Chem. 1985, 30, 2966.

30. JCPDS (Joint Committee on Powder Diffraction Standards), File $\mathrm{n}^{\mathrm{o}}$ 110005 (sodium bismuthate dihydrate), 2001.

31. JCPDS (Joint Committee on Powder Diffraction Standards), File $\mathrm{n}^{\mathrm{o}}$ 110006 (sodium bismuthate), 2001.

32. Battle, P. D.; Cattow, C. R. A.; Drennan, J.; Murray, A. D.; J. Phys. C: Solid State Phys. 1983, 16, L561.

33. JCPDS (Joint Committee on Powder Diffraction Standards), File $\mathbf{n}^{\circ}$ 031074 (sodium oxide), 2001.

34. JCPDS (Joint Committee on Powder Diffraction Standards), File $\mathrm{n}^{\mathrm{o}}$ 720398 (bismuth oxide), 2001.

35. Kucek, K. T.; César-Oliveira, M. A. F.; Wilhelm, H. M.; Ramos, L. P.; J. Am. Oil Chem. Soc. 2007, 84, 385.

36. Domingos, A. K.; Saad, E. B.; Wilhelm, H. M.; Ramos, L. P.; Bioresour. Technol. 2008, 99, 1837. 